\title{
Reliability of measurements on virtual models obtained from scanning of impressions and conventional plaster models
}

\author{
Débora Duarte Moreira ${ }^{1}$, Bruno Frazão Gribel ${ }^{1}$, Gina Delia Roque Torres ${ }^{1}$, Karla de Faria Vasconcelos ${ }^{1}$, \\ Deborah Queiroz de Freitas ${ }^{1}$, Gláucia Maria Bovi Ambrosano²
}

\begin{abstract}
${ }^{1}$ Universidade Estadual de Campinas - UNICAMP, Piracicaba Dental School, Departament of Oral Diagnosis, Area of Oral Radiology, Piracicaba, SP, Brazil
${ }^{2}$ Universidade Estadual de Campinas - UNICAMP, Piracicaba Dental School, Departament of Community and Preventive Dentistry, Area of Biostatistics,
\end{abstract}

Piracicaba, SP, Brazil

\begin{abstract}
Aim: To evaluate the reliability of linear measurements in virtual models by comparing measurements performed on virtual models obtained from alginate impression scans, plaster model and measurements performed on conventional plaster model. Methods: The sample comprised 26 randomly selected patients to have impressions of their upper and lower jaws taken using alginate and their bite registration using a wax bite. The virtual models were obtained by scanning the alginate impression and the plaster model in a laser surface scanner (R700; 3Shape, Copenhagen, Denmark), and the measurements were performed using the Ortho Analyser (3Shape) proprietary software. The linear measurements of the size of the teeth mesial to distal, arch perimeter, intercanine distance and intermolar distance in the upper and lower arches were performed on plaster models, digital impressions and digital models, by three observers and repeated after 15 days on 8 models for intra-observer evaluations. Data were tabulated and analyzed statistically. Intra-class correlation to check the agreement of intra and inter-observers and ANOVA test were used to analyze the differences between measurements of digital models from impression and digital models from plaster. Results: The results showed a statistically significant difference (pd"0.05) for the posterior teeth, anterior teeth, upper arch perimeter and lower inter-canine distance, comparing the digital models with plaster models, but these differences are considered clinically non-significant. Conclusions: Digital models were proven be reliable and clinically acceptable for measuring tooth width, perimeter arches, intercanine and intermolar distances.
\end{abstract}

Keywords: diagnosis; orthodontics; dental models; digitalis.

\section{Introduction}

Received for publication: September 02, 2014 Accepted: December 05, 2014

Correspondence to: Débora Duarte Moreira Faculdade de Odontologia de Piracicaba UNICAMP

Departamento de Diagnóstico Oral Avenida Limeira, 901 - Caixa Postal 52 CEP: 13414-903 - Piracicaba, SP, Brasil

Phone: +55 1921065327

e-mail: dededm@hotmail.com
The study of plaster models is an essential prerequisite for successful orthodontic treatment planning ${ }^{1-2}$. Traditionally, information is gathered from plaster orthodontic models, direct measurement or $2 \mathrm{D}$ photographs and radiographs ${ }^{3-5}$. However, analyzing plaster models can be a time-consuming procedure ${ }^{3}$.

Since 1990, digital technology is becoming part of the orthodontic records in many orthodontic practices. In order to improve the quality and efficiency of the record-taking consultation, digital photos, $\mathrm{x}$-rays and more recently 3D study models are becoming the standard orthodontic record in many practices across the world $^{6-9}$.

More recently companies have developed scanning technologies to produce 
digital models not only by direct plaster model scans but also direct alginate impression scans. These digital models can be used for visualization as well as for taking digital measurements using proprietary software ${ }^{4}$. Moreover, no physical space is necessary to store the records and they facilitate retrieving and sharing information with dental labs and colleagues in multidisciplinary treatments, contributing also for better practice management ${ }^{6-8}$. On the other hand, digital models require investment in hardware acquisition and training for hardware/software correct manipulation ${ }^{4,10,12}$.

Few studies have looked at the accuracy, reproducibility and reliability of measurements taken from 3D digital models in order to validate its use in the routine orthodontic practices ${ }^{1,3,5,8,10}$. The accuracy and reproducibility of such measurements may be influenced by a number of factors including tooth position (rotation, inclination and angulations), anatomical variations, position of the interproximal contact points, as well as inter-examiner variability due to lack of familiarity with the software ${ }^{4}$. The reliability of measurements on virtual models may also be influenced by some factors such as scanners and softwares.

The use of digital models is of great interest to all orthodontic practitioners, particularly if the impression can be scanned and the plaster models are not required to be poured, trimmed and polished. Some studies evaluated the reliability of measurements obtained of digital models from plaster models $s^{3,4,6-7,10-11,13-14}$. However, there are no studies that evaluated the reliability of digital models scanned by this kind of scanner and from alginate impression.

The aim of this study was to evaluate the reliability of linear measurements in virtual models by comparing measurements taken from plaster model with those taken from digital models obtained by two different scanning methods: 1) direct plaster model scan and 2) direct impression model scan.

\section{Material and methods}

This study was approved by the Ethics Committee in Research of the State University of Campinas (protocol \# 120/2011). A sample size of 26 individuals was statistically determined to be adequate. Subjects were on average 34.7 years of age (18 to 58 years-old) and reported to a radiology clinic for regular orthodontic record taking. A written consent was obtained from each patient.

\section{Acquisition of Models}

Impressions of the upper and lower arches were taken using Ortho print (Zhermack, Rovigo, Italy) and their bites registered using conventional utility wax $1 \mathrm{~mm}$. The inclusion criterion was permanent dentition without braces bonded to the teeth. Patients with removable dentures were requested to remove it so that the impression and bite registration could be taken.

All scans (impressions and models) were made using a surface laser scanner R700 (3Shape, Copenhagen, Denmark).
The scanner was calibrated using the recommended calibration kit twice daily to ensure that the optimal accuracy claimed by the manufacturer $(20 \mu \mathrm{m})$ could be reached.

The scans were made according to the manufacturer's instructions in the handbook. First the upper impression was placed inside the scanner using the impression holding fixture. Next, after the automated scanning of the upper impression, the lower impression was placed inside the scanner. At last, the bite record was placed inside the scanner using the bite registration fixture and scanned. The total scanning time including the creation of a virtual base was approximately $40 \mathrm{~min}$.

After the impressions were scanned, the plaster model was poured (using conventional white plaster) and an upper and lower model was also scanned separately. After the upper and lower models were placed in occlusion using the bite registration, the set was scanned using the 2-cast fixture, provided by the scanner manufacturer. The total scanning time including the creation of a virtual base was approximately $30 \mathrm{~min}$.

\section{Model Analysis}

Three different observers that had a short 5-case training for calibration purposes performed the measurements. Each observer was trained independently and the 5 cases used for this purpose were not included in this study.

All measurements were taken in the following order: plaster models, alginate impression scans and plaster model scans. Each observer measured 3 sets (upper and lower) of models per day. The plaster models were measured using a digital caliper (SC-6 Digital Caliper, Mitutoyo Corporation, Tokyo, Japan) and all digital measurements were made using Ortho Analyser software (3Shape).

The measurements used in this study were:

- Tooth Width (greatest mesial-distal distance, measured from the buccal view);

- Intercanine Distance - ICD (distance between the right and left canine incisor tip).

- Intermolar Width - IMD (Distance between the right and left first molar lingual/palatal sulcus).

- Arch Perimeter - AP (sum of the distance between the mesial of the first molar to the distal of the canines and the distal of the canines to the mesial of the central incisors, measured at the papilla level).

A total of 731 measurements were taken from the 26 model sets. Eight model sets were randomly chosen to be reassessed by the observers within a period of 15 days to verify the reproducibility of the measurements.

\section{Statistical Analysis}

Data were analyzed using SAS software 9.1 (SAS Institute, Cary, NC, USA). The intraclass correlation coefficient (ICC) was calculated for the intra- and interobserver agreement. All measurements were analyzed statistically using ANOVA with Tukey correction. The significance level was $5 \%$. 


\section{Results}

\section{Intra- and inter-observer agreement}

The values of ICC were good or excellent, according to Szklo and Nieto ${ }^{15}$.The intra-observer agreement of the observer 1 varied from 0.78 to 1.00 ; observer 2 varied from 0.74 to 1.00 and observer 3 from 0.75 to 1.00 .

The observer agreement varied from 0.53 to 1.00 for the plaster models measurements; from 0.51 to 1.00 for the impression models scans and from 0.68 to 0.99 for the plaster model scans.

\section{Digital Models Accuracy}

Table 1 shows the means and standard deviations (SD) of all measurements. There was a statistically significant difference between the tooth width measurements, upper arch perimeter and lower intercanine distance between the digital and plaster models.
There was no statistically significant difference between the measurements taken from the maxillary and mandibular anterior tooth width $(\mathrm{p}>0.05)$ except from tooth 42 and 43. There were also no statistically significant differences between the maxillary intercanine and intermolar width and mandibular dental arch perimeter $(p>0.05)$

The greatest differences were found in the maxillary and mandibular posterior tooth width. The differences on the maxillary arch length, mandibular intercanine and intermolar distances were also statistically significant. All differences are listed in the descriptive statistics in Table 2.

\section{Discussion}

Analyzing study models is a key factor for a good orthodontic diagnosis and successful orthodontic treatment plan, because it enables not only the analysis of the present and the required space for the correct leveling and aligning

Table 1. Descriptive statistics and results of the statistical analysis of the measurements performed on the plaster model, virtual molding and virtual model

\begin{tabular}{|c|c|c|c|c|c|c|c|c|c|}
\hline \multirow[t]{2}{*}{ Tooth } & \multicolumn{3}{|c|}{ Plaster Model } & \multicolumn{3}{|c|}{ Impression scan } & \multicolumn{2}{|c|}{ Model scan } & \multirow[b]{2}{*}{$\begin{array}{l}\text { IC } 95 \%{ }^{\#} \\
\text { deviation }\end{array}$} \\
\hline & Mean & $\begin{array}{l}\text { Standard } \\
\text { deviation }\end{array}$ & IC $95 \%{ }^{\#}$ & Mean & Standard & $\begin{array}{l}\text { IC } 95 \%{ }^{\#} \\
\text { deviation }\end{array}$ & Mean & Standard & \\
\hline T16 & $9.78 \mathrm{C}$ & 0.58 & $9.54-10.02$ & $10.21 \mathrm{~A}$ & 0.66 & $9.93-10.48$ & $9.99 \mathrm{~B}$ & 0.60 & $9.74-10.23$ \\
\hline T15 & $6.56 \mathrm{~B}$ & 0.53 & $6.35-6.78$ & $6.86 \mathrm{~A}$ & 0.38 & $6.71-7.01$ & $6.80 \mathrm{~A}$ & 0.43 & $6.63-6.97$ \\
\hline T14 & $6.91 \mathrm{C}$ & 0.50 & $6.69-7.12$ & $7.18 \mathrm{~A}$ & 0.54 & $6.94-7.41$ & $7.06 \mathrm{~B}$ & 0.53 & $6.83-7.28$ \\
\hline T13 & $7.77 \mathrm{~A}$ & 0.39 & $7.62-7.93$ & $7.81 \mathrm{~A}$ & 0.43 & 7.64-7.98 & $7.77 \mathrm{~A}$ & 0.48 & $7.57-7.97$ \\
\hline T12 & $6.50 \mathrm{~A}$ & 0.87 & $6.14-6.86$ & $6.52 \mathrm{~A}$ & 0.79 & $6.20-6.85$ & $6.50 \mathrm{~A}$ & 0.80 & $6.17-6.83$ \\
\hline T11 & $8.43 \mathrm{~A}$ & 0.54 & $8.21-8.64$ & $8.43 \mathrm{~A}$ & 0.51 & $8.22-8.63$ & $8.44 \mathrm{~A}$ & 0.56 & $8.22-8.67$ \\
\hline T21 & $8.48 \mathrm{~A}$ & 0.62 & $8.23-8.73$ & $8.47 \mathrm{~A}$ & 0.54 & $8.25-8.69$ & $8.44 \mathrm{~A}$ & 0.60 & $8.20-8.69$ \\
\hline T22 & $6.45 \mathrm{~A}$ & 0.79 & $6.13-6.77$ & $6.49 \mathrm{~A}$ & 0.76 & $6.18-6.80$ & $6.53 \mathrm{~A}$ & 0.82 & $6.20-6.87$ \\
\hline T23 & $7.71 \mathrm{~A}$ & 0.42 & $7.54-7.88$ & $7.63 \mathrm{~A}$ & 0.47 & $7.44-7.82$ & $7.69 \mathrm{~A}$ & 0.52 & $7.48-7.90$ \\
\hline T24 & $6.84 \mathrm{~B}$ & 0.48 & $6.64-7.05$ & $7.04 \mathrm{~A}$ & 0.49 & $6.84-7.25$ & $7.07 \mathrm{~A}$ & 0.48 & $6.86-7.27$ \\
\hline T25 & $6.41 \mathrm{~B}$ & 0.57 & $6.17-6.65$ & $6.65 \mathrm{~A}$ & 0.52 & $6.43-6.87$ & $6.66 \mathrm{~A}$ & 0.61 & $6.40-6.92$ \\
\hline T26 & $9.72 \mathrm{~B}$ & 0.64 & $9.45-9.99$ & $9.93 \mathrm{~A}$ & 0.61 & $9.67-10.19$ & $9.92 \mathrm{~A}$ & 0.68 & $9.64-10.21$ \\
\hline T36 & $11.02 \mathrm{~B}$ & 0.68 & $10.70-11.33$ & $11.35 \mathrm{~A}$ & 0.62 & $11.06-11.64$ & $11.34 \mathrm{~A}$ & 0.61 & $11.06-11.62$ \\
\hline T35 & $7.06 \mathrm{~B}$ & 0.78 & $6.73-7.39$ & $7.39 \mathrm{~A}$ & 0.73 & $7.08-7.70$ & $7.28 \mathrm{~A}$ & 0.78 & $6.96-7.61$ \\
\hline T34 & $6.79 \mathrm{~B}$ & 0.55 & $6.55-7.03$ & $7.02 \mathrm{~A}$ & 0.51 & $6.79-7.24$ & $7.07 \mathrm{~A}$ & 0.55 & $6.83-7.31$ \\
\hline T33 & $6.77 \mathrm{~A}$ & 0.35 & 6.63-6.91 & $6.83 \mathrm{~A}$ & 0.41 & $6.66-6.99$ & $6.81 \mathrm{~A}$ & 0.39 & $6.65-6.97$ \\
\hline T32 & $5.81 \mathrm{~A}$ & 0.51 & $5.60-6.01$ & $5.75 \mathrm{~A}$ & 0.46 & $5.57-5.94$ & $5.87 \mathrm{~A}$ & 0.40 & $5.71-6.03$ \\
\hline T31 & $5.28 \mathrm{~A}$ & 0.50 & $5.07-5.48$ & $5.29 \mathrm{~A}$ & 0.52 & $5.08-5.50$ & $5.40 \mathrm{~A}$ & 0.46 & $5.21-5.58$ \\
\hline T41 & $5.28 \mathrm{~A}$ & 0.35 & $5.14-5.43$ & $5.34 \mathrm{~A}$ & 0.40 & $5.18-5.50$ & $5.35 \mathrm{~A}$ & 0.37 & $5.20-5.51$ \\
\hline T42 & $5.85 \mathrm{~B}$ & 0.51 & $5.64-6.06$ & $5.86 \mathrm{~B}$ & 0.46 & $5.67-6.05$ & $6.01 \mathrm{~A}$ & 0.55 & $5.78-6.23$ \\
\hline T43 & $6.66 \mathrm{~B}$ & 0.41 & $6.49-6.82$ & $6.75 \mathrm{~A}$ & 0.42 & $6.58-6.92$ & $6.77 \mathrm{~A}$ & 0.41 & $6.60-6.94$ \\
\hline T44 & $6.76 \mathrm{~B}$ & 0.51 & $6.55-6.98$ & $7.03 \mathrm{~A}$ & 0.63 & $6.77-7.30$ & $6.91 \mathrm{AB}$ & 0.54 & $6.69-7.14$ \\
\hline T45 & $6.87 \mathrm{~B}$ & 0.60 & $6.61-7.13$ & $7.13 \mathrm{~A}$ & 0.64 & $6.85-7.41$ & $7.18 \mathrm{~A}$ & 0.58 & $6.93-7.43$ \\
\hline T46 & $11.03 \mathrm{~B}$ & 0.58 & $10.76-11.30$ & $11.31 \mathrm{~A}$ & 0.61 & $11.02-11.60$ & $11.37 \mathrm{~A}$ & 0.66 & $11.06-11.68$ \\
\hline UAP & $71.99 \mathrm{~B}$ & 4.43 & $70.20-73.79$ & $73.12 \mathrm{~A}$ & 4.34 & $71.36-74.87$ & $73.06 \mathrm{~A}$ & 4.54 & $71.23-74.89$ \\
\hline UICD & $33.16 \mathrm{~A}$ & 2.29 & $32.23-34.08$ & $33.06 \mathrm{~A}$ & 2.17 & $32.19-33.94$ & $33.22 \mathrm{~A}$ & 2.18 & $32.34-34.10$ \\
\hline UIMD & $40.01 \mathrm{~A}$ & 3.88 & $38.34-41.69$ & $39.77 \mathrm{~A}$ & 3.17 & $38.40-41.14$ & $39.98 \mathrm{~A}$ & 3.24 & $38.58-41.38$ \\
\hline LAP & $63.33 \mathrm{~A}$ & 5.71 & $60.86-65.80$ & $65.15 \mathrm{~A}$ & 4.46 & $63.22-67.07$ & $64.64 \mathrm{~A}$ & 5.80 & $62.13-67.15$ \\
\hline LICD & $25.50 \mathrm{~B}$ & 2.03 & $24.68-26.32$ & $26.32 \mathrm{~A}$ & 1.98 & 25.52-27.12 & $26.01 \mathrm{~A}$ & 2.10 & $25.16-26.86$ \\
\hline LIMD & $36.08 \mathrm{~B}$ & 3.33 & $34.37-37.80$ & $36.21 \mathrm{~B}$ & 3.40 & $34.45-37.96$ & $36.92 \mathrm{~A}$ & 3.40 & $35.18-38.67$ \\
\hline
\end{tabular}

\#Confidence Interval of 95\%. Means followed by different letters horizontally differ $(p<0.05)$. Cl, confidence interval; T, tooth; UAP, upper arch perimeter; UICD, maxillary intercanine distance; UIMD, maxillary intermolar distance; LAP, mandibular arch perimeter; LICD, mandibular intercanine distance; LIMD, mandibular intermolar distance. 
Table 2. Differences between the digital models and the plaster models

\begin{tabular}{|c|c|c|c|}
\hline Measurement & Plaster $\mathrm{x}$ Impression scan (mm) & Plaster x Model scan (mm) & Model scan $\mathrm{x}$ Impression scan (mm) \\
\hline D16 & 0.43 & 0.21 & 0.22 \\
\hline D15 & 0.30 & 0.24 & $一^{*}$ \\
\hline D14 & 0.27 & 0.15 & 0.12 \\
\hline D24 & 0.20 & 0.23 & $-^{*}$ \\
\hline D25 & 0.24 & 0.25 & $一^{*}$ \\
\hline D26 & 0.21 & 0.20 & $-^{*}$ \\
\hline D36 & 0.33 & 0.32 & $-^{*}$ \\
\hline D35 & 0.33 & 0.22 & $-^{*}$ \\
\hline D34 & 0.28 & 0.23 & $-^{*}$ \\
\hline D42 & $-^{*}$ & 0.16 & 0.15 \\
\hline D43 & 0.09 & 0.11 & $一^{*}$ \\
\hline D44 & 0.27 & $一^{*}$ & $一^{*}$ \\
\hline D45 & 0.26 & 0.31 & $-^{*}$ \\
\hline D46 & 0.28 & 0.34 & $-^{*}$ \\
\hline PAS & 1.13 & 1.07 & - $^{*}$ \\
\hline $\mathrm{DICl}$ & 0.82 & 0.51 & - $^{*}$ \\
\hline DIMI & - $^{*}$ & 0.84 & 0.71 \\
\hline
\end{tabular}

-* No statistically significant difference

of the teeth, but also the individual tooth sizes and discrepancies that can ultimately lead to a poor indentation of the occlusion. Furthermore, the anatomical variations observed on a plaster model can help for a better position of brackets either using direct or indirect bonding, determine the need for tooth extraction or maxillary expansions.

Traditionally, most of the information required for an orthodontist to develop a diagnosis and treatment plan comes from photographs, radiographic images and measurements obtained directly from the patient's mouth or from plaster $\operatorname{models}^{3-5}$.

Recent technological advancements allowed these 3D measurements to be made digitally using virtual study models scanned from plaster models or alginate impressions ${ }^{5,16}$. Some studies evaluated the accuracy and validity of measurements obtained of digital models from plaster models $\mathrm{s}^{3-4,6-7,70-11,13-14,16}$. However, we emphasize that there are no studies that evaluated the reliability of digital models scanned from alginate impression.

The total scanning time was of particular interest in this study. Although the instruction handbook says it takes from 2 to $3 \mathrm{~min}$ to scan a plaster model and 7-10 min to scan an impression, the total scanning time was greater than initially expected because it involves virtual reconstructions, virtual trimming and virtual base creation. These processes are very dependent on the used hardware and the experience of the operator.

In the present study the measurements of both different virtual model sets were compared to those of the physical plaster model, with was judged to be the gold standard, since it would be ethically and clinically impossible to obtain the exact tooth measurements to be used as the gold standard ${ }^{1-}$ $2,8-9,11,16$. The statistically significant differences found in some measurements can be partially explained by the fact that even though the alginate used in this study has a high stability, in the first $100 \mathrm{~h}$, some contraction may have occurred from the time the impression was scanned to the time the models were poured and expansion caused by the plaster once it hardens. Another influence could be the disinfection process of the alginate impressions, ${ }^{4,9-11}$.

Additionally, in this study the observers were not trained orthodontists but radiologists and possibly had some difficulties placing the landmarks on more crowded dentitions due to increased overlapping, rotation and inclination of the teeth ${ }^{4,11,13-14}$. This makes it more difficult to exactly identify the same landmarks at the contact points in the interproximal areas and duplicate them exactly on 3 different model sets. ${ }^{4-5,11,13-14}$

Although the intra-class correlation was high for all groups indicating a high reproducibility, the differences between the digital and physical group was greater than the differences between the two digital groups. This could be due to the fact that the two digital model sets, differently from the physical model set, allow the observer to enhance visualization, zoom and maintain each landmark at the exact same position while performing a measurement. ${ }^{10-11,14}$

In this study the most of significant differences were found in the posterior region with overestimation of the measurements. This may have occurred due to the scanning precision, since the positioning of cameras and laser beam can be less accurate in this region causing image distortion.

Stevens et al. ${ }^{11}$ have advocated that the measurements in digital models could be more accurate than those made on plaster models, because they are not limited by the physical limitations of the caliper at the landmarks.

In spite of having found a number of statistically significant differences between the plaster model tooth width measurements and those made on the digital models ( 0.09 $\mathrm{mm}$ to $0.43 \mathrm{~mm}$ ), according to Santoro et al. ${ }^{10}$ and Leifert et al. ${ }^{4}$ differences smaller than $0.5 \mathrm{~mm}$, can be considered clinically insignificant. 

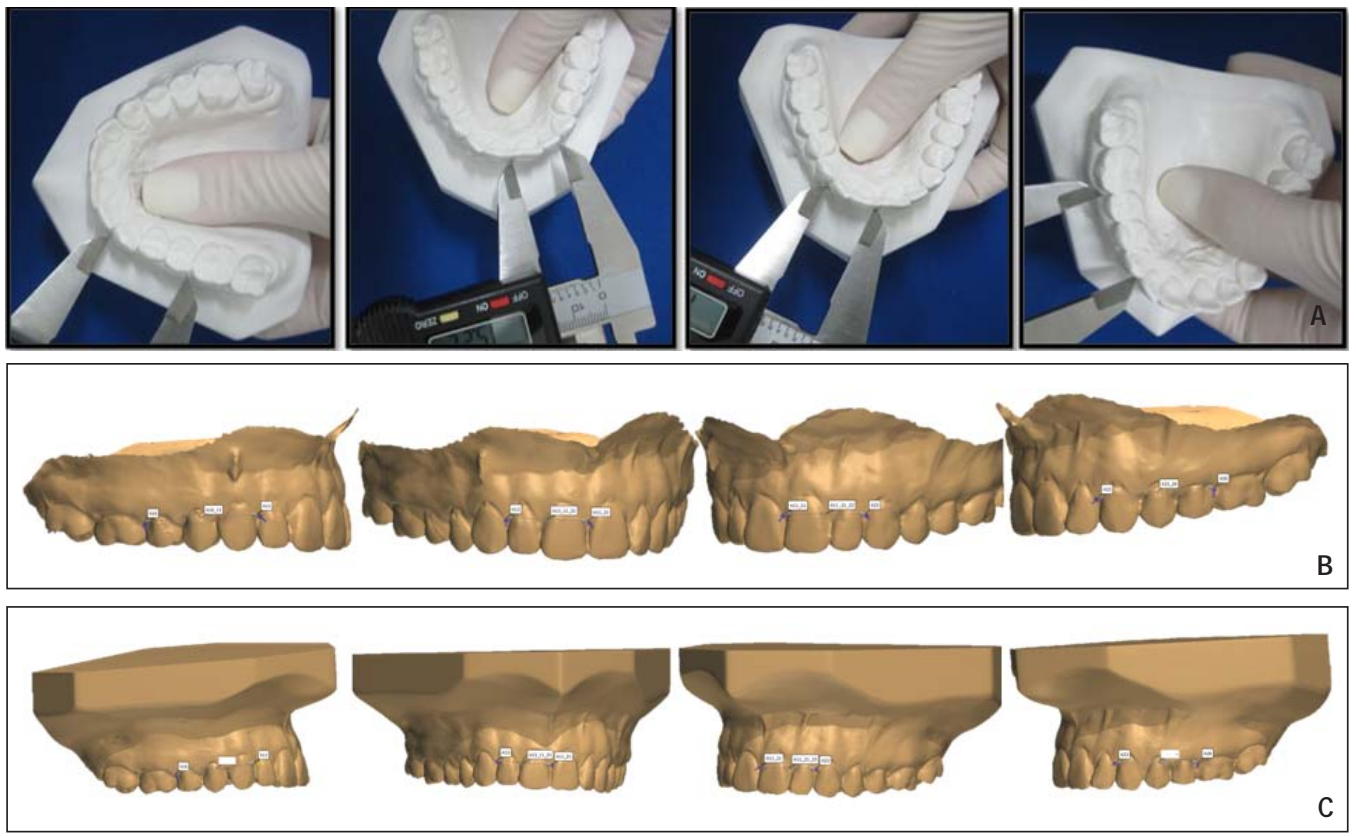

Fig. 1. Landmarks and caliper measurements used to determine the arch perimeter on the 3 different model sets: plaster model (A), impression model scan (B) and model scan (C).

In the present study the greatest differences $(0,51 \mathrm{~mm}$ to $1,13 \mathrm{~mm})$ were found on the linear measurements: maxillary arch perimeter (UAP), maxillary intercanine distance (UICD), maxillary intermolar distance (UIMD), mandibular arch perimeter (LAP), mandibular intercanine distance (LICD), mandibular intermolar distance (LIMD). These measures have greater difference because they are measurements at greater distances.

Moreover, according to Tomassetti et al. ${ }^{17}$ and Wiranto et al. ${ }^{9}$, only differences greater than $1.5 \mathrm{~mm}$ are considered clinically significant. Although this may be true in some cases, but if one wishes to use these digital models further for appliance production this threshold may be too high, one could want to keep these differences to a minimum.

The use of digital models can lead to numerous advantages in the daily orthodontic practice. The files can be easily stored, retrieved and shared, improving patient communication and data sharing with orthodontic labs and other players in multidisciplinary cases. The measurements taken from the digital files are accurate and reproducible making this type of record likely to become rapidly the standard of treatment planning in orthodontics.

In conclusion, although some measurements of digital models were different from those obtained from plaster models in the studied scanner, virtual models from either plaster model scans or alginate impression scans are reliable and sufficiently accurate for orthodontic diagnosis and treatment planning, since the differences agree with the literature.

\section{Acknowledgements}

We would like to acknowledge CAPES for the financial support.

\section{References}

1. Luu NS, Nikolcheva LG, Retrouvey JM, Flores-Mir C, El-Bialy T, Carey JP, Major PW. Linear measurements using virtual study models. A systematic review. Angle Orthod. 2012; 82: 1098-1106.

2. Luu NS, Mandich MA, Flores-Mir C, El-Bialy T, Heo G, Carey JP, Major PW. The validity, reliability, and time requirement of study model analysis using cone-beam computed tomography-generated virtual study models. Orthod Craniofac Res. 2014; 17: 14-26.

3. Zilberman O, Huggare JAV, Parikakis KA. Evaluation of the validity of tooth size and arch width measurements using conventional and threedimensional virtual orthodontic models. Angle Orthod. 2003; 73: 301-6.

4. Leifert MF, Leifert MM, Efstratiadis SS, Cangialosi TJ. Comparasion of space analysis evaluations with digital models and plaster dental casts. Am J Orthod Dentofacial Orthop. 2009; 136: 16.e1-4.

5. El-Zanaty HM, El-Beialy AR, El-EzZ, AMA, Attia, KH, El-Bialy AR, Mostafa YA. Three-dimensional dental measurements: An alternative to plaster models. Am J Orthod Dentofacial Orthop. 2010; 137: 259-65.

6. Whetten JL, Williamson PC, Heo G, Varnhagen C, Major PW. Variations in orthodontic treatment planning decisions of Class II patients between virtual 3-dimensional models and traditional plaster study models. Am J Orthod Dentofacial Orthop. 2006; 130: 485-91.

7. Okunami TR, Kusnoto B, BeGole E, Evans CA, Sadowsky C, Fadavi S. Assessing the American Board of Orthodontics objective grading system: Digital vs plaster dental casts. Am J Orthod Dentofacial Orthop. 2007; 131: 51-6.

8. Akyalcin S, Dyer DJ, English JD, Sar C. Comparison of 3-dimensional dental models from different sources: Diagnostic accuracy and surface registration analysis. Am J Orthod Dentofacial Orthop. 2013; 144: 831-7.

9. Wiranto MG, Engelbrecht WP, Nolthenius HET, Meer WJ, Ren Y. Validity, reliability, and reproducibility of linear measurements on digital models obtained from intraoral and cone-beam computed tomography scans of alginate impressions. Am J Orthod Dentofacial Orthop. 2013; 143: 140-7.

10. Santoro M, Galkin S, Teredesai M, Nicolay OF, Cangialosi TJ. Comparison of measurements made on digital and plaster models. Am J Orthod Dentofacial Orthop. 2003; 124: 101-5.

11. Stevens DR, Mir CF, Nebbe B, Raboud DW, Heo G, Major PW. Validity, realiability, and reproducibility of plaster vs digital study models: Comparison of peer assessment rating and Bolton analysis and their constituent measurements. Am J Orthod Dentofacial Orthop. 2006; 129: 794-803. 
12. Brusco N, Andreetto M, Lucchese L, Carmignato S, Cortelazzo GM. Metrological validation for 3D modeling of dental plaster casts. Med Eng Phys. 2007; 29: 954-66.

13. Costalos PA, Sarraf k, Cangialosi TJ, Efdtratiadis S. Evaluation of the accuracy of digital model analysis for the American Board of Orthodontics objective grading system for dental casts. Am J Orthod Dentofacial Orthop. 2005; 128: 624-9.

14. Sousa MV, Vasconcelos EC, Janson G, Garib D, Pinzan A. Accuracy and reproducibility of 3-dimensional digital model measurements. Am J Orthod Dentofacial Orthop. 2012; 142: 269-73.

15. Szklo R, Nieto FJ. Epidemiology Beyond the Basis. Aspen Publications; 2000. p. 343-404.

16. Lione R, Buongiorno M, Franchi L, Cozza P. Evaluation of maxillary arch dimensions and palatal morphology in mouth-breathing children by using digital dental casts. Int J Pediatr Otorhinolaryngol. 2014; 78: 91-5.

17. Tomassetti JJ, Taloumis LJ, Denny JM, Fischer JR Jr. A comparison of 3 computerized Bolton tooth-size analyses with a commonly used method. Angle Orthod. 2001; 71: 351-7. 